\title{
STUDY ON THE FORTIFICATION TECHNIQUES OF MULTIPLE FOOD PRODUCTS USING IMMUNITY BOOSTING MICRONUTRIENTS AND ANTIOXIDANTS: A LITERATURE REVIEW
}

\author{
Kakali Bandyopadhyay \\ H.O.D and Associate Professor \\ Department of Food technology \\ Guru Nanak Institute of Technology \\ Kolkata, India. \\ Mariya Mukherjee, Pulak Deb, Akash Biswas, Riya Kumari Gope, Sweta Das \\ UG Students \\ Department of Food technology \\ Guru Nanak Institute of Technology \\ Kolkata, India
}

\begin{abstract}
During this ongoing period of the devastating pandemic of COVID-19 caused by Novel Coronavirus, the term "Immunity" has become quite a catchword, and a strong and healthy immune system has become the need of the hour to build up our body resistance against pathogens and provide protection against them. Researches on various nutritional components and their bioavailability point to the fact that there are several micronutrients and trace elements whose intake through diet can help in triggering up the functioning of the immune system. Nowadays, as per the Food Safety and Standards (Fortification of Foods) Regulations, it is also advised that we must buy and consume products that have the " $+F "$ logo or fortification logo which means that those products are enriched in certain added vitamins and trace metals from which the benefits of a stronger immune response can be obtained. It has been observed that among the vitamins, vitamin $A, C, D$ and $E$ and the mineral zinc play a significant role in boosting up the immune response through their interactions with the cells of the immune system. Also, antioxidants like $\beta$-carotene, anthocyanins, etc play a major role in the immune system functioning by lowering down the level of oxidative stresses in the body. These immunity boosting vitamins, minerals and antioxidants can be incorporated into regular food products through the method of fortification of the products or even, they can be added into an immunity boosting drink, powder or supplements. Various researches and reviews demonstrate how these micronutrients can be added or incorporated into a food product; they can be obtained from artificial/synthetic sources or natural sources like fruits containing these
\end{abstract}

vitamins and minerals can be used as functional ingredients in the products. Sometimes, multivitamins or minerals can be incorporated into the same product. Therefore, the following review will be based on the study of the methods in which various products have been fortified from time to time with immunity boosting nutrients like vitamins $A, C, D$ and $E$, zinc and antioxidants as demonstrated in numerous research work. It will be a detailed study on the techniques followed during the fortification procedures as well as the sources from which those micronutrients and antioxidants are obtained. The roles played by the micronutrients in building immunity will also be discussed.

Index Terms - Immunity, Fortification, Bioavailability, Vitamins, Micronutrients, Antioxidants, Minerals, Regular food products

\section{INTRODUCTION}

Immunity is the body's internal capability to resist the harmful effects of an invading pathogenic microorganism or even minimize the effects of infections caused by them. It is mostly an internal factor of the body and the strength of a person's immunity depends mainly on the strength of the immune response generated by his immune cells. However, there are certain micronutrients which are observed to enhance this overall functioning of the immune system and these elements are mostly obtained from consuming foods which are rich in them. The vitamins A, C, D, E and the mineral zinc are the micronutrients which are observed to perform such immunity boosting activities. Each of these micronutrients hasits own distinct mechanism through which it triggers the 


\section{International Journal of Engineering Applied Sciences and Technology, 2020 \\ Vol. 5, Issue 6, ISSN No. 2455-2143, Pages 163-169 \\ Published Online October 2020 in IJEAST (http://www.ijeast.com)}

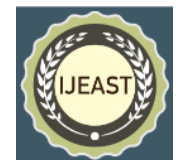

immune system. But the fact is that, these micronutrients have specific foods in which they are found in rich amounts; while in other food items, their quantity is extremely less or they are absent. This is due to the reason that the nutritional composition of every food item is different from each other. So in order to intake a fair proportion of these immunity boosting micronutrients, it is necessary to incorporate those particular food items enriched in them into the diet on a regular basis which is not always possible. Also, certain staple food items like rice, bread, milk, edible oils, etc have a very poor quantity of all these above mentioned micronutrients. Since these are the food items that are consumed on a regular basis, it is necessary to incorporate those immunity boosting vitamins and minerals into them so that the need of arranging for special food products sufficient in those elements is eliminated. This incorporation of the immunity boosting micronutrients into the staple food items can be achieved through the process of fortification. Fortification is basically the addition or incorporation of micronutrients like vitamins and minerals into any food item so as to enhance its nutritional composition and make up for the deficiency of any particular micronutrient in them.

Fortification can be done in a number of ways and the source from which the desired micronutrient is obtained can be a natural or an artificial source. Several research works that we have studied shows that whenever vitamin $\mathrm{C}$ or vitamin $\mathrm{D}$ forms are to be fortified into a product, commercially produced dry vitamin powders are mostly preferred over natural sources. Sometimes, natural sources are also used from which the micronutrients are either extracted or the source itself is added to the food. Speaking of the ways in which micronutrients are fortified, it is observed that often vitamin is encapsulated before adding it to a food that will undergo heat treatment as this procedure will increase the stability of the vitamin. Likewise, there are many other fortification techniques of staple food items where the micronutrient is made to undergo certain processes before fortification so that its stability in the food is ensured. Apart from these immunity boosting micronutrients, antioxidants also exhibit immunity boosting activity by their free radical scavenging action in our body. They can also be added to the food and they are mainly extracted from natural sources. In this review paper, we have given a thorough study of the processes used by different researchers to fortify vitamins A, $\mathrm{C}, \mathrm{D}$ and $\mathrm{E}$, zinc and antioxidants into foods like dairy products, breads, etc. We have also discussed the roles played by these compounds in actually strengthening our immune response and what are the difficulties faced during their fortification as well as how to overcome those difficulties. In total, this review will be helpful in understanding the nutrients that can be fortified into an immunity boosting product like a drink or a powder, what are the sources of those nutrients that can be utilized for better results and the methods that can be adopted for their fortification into a particular food product.

\section{ROLES PLAYED BY THESPECIFIED VITAMINS (A, C, D, E) IN IMMUNITY BOOSTING}

The first micronutrient to be discussed here, Vitamin A, generates its immunity boosting responses in a number of ways. Vitamin A is mainly responsible for the formation and the maturation of the epithelial cells "McCullough et. al. (1999)" [1]. These cells form the epithelial lining of most of the organs of the body which serve as the first line of defense against the invading pathogenic microorganisms. Vitamin $\mathrm{C}$ is suggested to be increasing the complement factor of our innate immunity which is said to generate an anti-bacterial activity in our body. It is known to enhance the processes of phagocytosis and chemotaxis to generate immune action "Chen et. al. (2009)" [2]. Several researches show that vitamin $\mathrm{D}$ is associated with the modulation of both the types of immunity - adaptive immunity, innate immunity "Aranow et. al. (2011)" [3].Lastly, Vitamin E is known to exhibit its immunity boosting action mainly by increasing the natural killer cell activity in the body and it also increases the level of immunoglobulin "Lee et. al. (2018)" [4].

\subsection{Fortification of Vitamin A into food products}

Vitamin A is an essential immunity boosting micronutrient which is fat soluble. Including retinols, retinals and retinoic acids, it comes in multiple forms. From the preformed retinoids, dietary vitamin A is absorbed as retinol. It is a crucial component for many important biological functions including growth, immunity, vision, etc "Polcz et. al. (2019)" [5]. For normal lung growth and integrity of respiratory tract epithelial cells, vitamin A plays a very major role. It reduces the rate of developing of chronic lung disease "Darlow et. al. (2016)" [6]. In food and pharmaceutical fields, vitamin A has been incorporated for the development of new products. But the poor solubility of this vitamin in aqueous systems, low polarity and high sensitivity are the main concerns that need to be overcome in food processing and in case of the storage of the food "Gonçalves et. al. (2017)" [7]. Nowadays, vitamin A deficiency (VAD) has become a serious issue. Deficiency of vitamin A is the main reason of Night blindness. Over the past 35 years, research has shown that VAD can lead to anemia, infections and a series of ocular symptoms "Wiseman et. al. (2017)" [8]. That is why food fortification is required to reduce the vitamin A deficiency. A cost-effective and simple strategy to implement is the fortification of vegetable oil with vitamin A. But a limiting factor in this case is the stability of vitamin A "Laillou et. al. (2012)" [9]. Tanzania mandated the fortification of oil in 2011 with vitamin A to solve the problem of the diseases caused because of vitamin A deficiency. But only $16 \%$ of edible oil met the standards for adequate fortification by 2015 "Walters et. al. (2019)" [10]. For the fortification of sugar with vitamin A, one discontinuous cooling crystallization process was developed. The results of the experiment showed that, the encapsulation of the retinyl palmitate seeds (Vitamin A) to fortify the sugar is possible "Quintana-Hernandez et. al. (2020)" [11]. And also for tackling vitamin A deficiency, 


\section{International Journal of Engineering Applied Sciences and Technology, 2020 \\ Vol. 5, Issue 6, ISSN No. 2455-2143, Pages 163-169 \\ Published Online October 2020 in IJEAST (http://www.ijeast.com)}

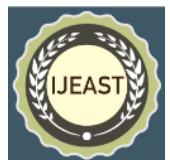

Biofortified Sweet Potato (OFSP) can be used as well. It is a rich plant-based source of beta-carotene that is converted into vitamin A by our body "Low et. al. (2007)" [12]. Fortification of lassi is also possible by using natural vegetable powders. As VAD control is a realizable goal right now that is why it can be an amazing step to fortify foods with vitamin A. As dairy products are not a pretty good source of vitamin A, so fortification of these products with vitamin A can provide a good nutrition to the body "Chawla et. al. (2018)" [13]. Another study has shown that the fortification of biscuits with Carrot powder is also possible. The preparation of Carrot powder can be done by blanching, tray drying and grounding the fresh carrots "Thomas et. al. (2018)" [14].

\subsection{Fortification of variable food products with Vitamin C}

Vitamin $\mathrm{C}$ is an important micronutrient that plays a major role in triggering the immune response of the immune system. It is very much abundant in citrus fruits like lime, lemon, and oranges. It is also found in ample quantities in fruits like mango, lime, pineapple and kiwi. It has been observed that vitamin C's immune system strengthening action comes from its ability to act as a potential antioxidant in the body and protect the body from the oxidative stresses in the environment as well as its ability to accumulate in the neutrophils and enhance the processes of chemotaxis and phagocytosis to kill the invading pathogenic microbes "Carr et. al. (2017) [15]. Due to these properties, vitamin $C$ can be incorporated as a functional element in staple food products or immunity boosting drinks and powders. It can be incorporated into dairy products in an encapsulated form as vitamin $\mathrm{C}$ content in milk and some milk products are low. The method in which liposomes containing encapsulated vitamin $\mathrm{C}$ can be fortified into raw milk has been demonstrated in details in Rajan Sharma and Darshan Lal's work "Sharma et. al. (2005)" [16]. It is based on the preparation of liposomes using egg phosphatidylcholine and then addition of encapsulated vitamin C (ascorbic acid) to the liposomes following Kirby's procedure of dehydration/rehydration "Kirby et. al. (1991)" [17]. Samples of liposomes were then tested for their vitamin $\mathrm{C}$ content and then their dilution in appropriate amount of PBS buffer was done. Finally, the diluted sample of liposomes with encapsulated vitamin $\mathrm{C}$ was added to raw buffalo milk and vitamin $\mathrm{C}$ fortified buffalo milk was obtained which was then tested for its thermal stability. Another research work was conducted where vitamin $\mathrm{C}$ was fortified into regular and low-fat samples of cottage cheese along with vitamin A. In this case, fortification of cottage cheese was done by the addition of 35mg of dry form of vitamin $\mathrm{C}$ along with vitamin A to the cream mix for the cheese and the mixture was stirred well. The mixture then underwent pasteurization and homogenization and was finally added in the curd to get the base for the fortified cheese "Sweeney et. al. (1989)" [18]. This fortification technique can serve as the perfect example where vitamin $\mathrm{C}$ is fortified into a regular dairy product at the time of processing of the product without undergoing encapsulation. However, in both these cases, fortification was done using vitamin $\mathrm{C}$ taken from artificial commercial sources (such as dry form of ascorbic acid in case of cottage cheese). Fortification can also be done with natural ingredients like fruits that have high content of vitamin $\mathrm{C}$ in them. For instance, beverages like fruit juices and lemonades can be fortified in this manner. A study conducted on fortification of lemonades shows how extracts prepared out of lemon verbena or Lippia citriodora were incorporated into regular lemonade along with other natural extracts like ginger (Zingiber officinale) and peppermint "Tamer et. al. (2017)" [19]. As mentioned earlier, mangoes are a good source of vitamin $\mathrm{C}$ other than the citrus fruits and fruits like Litchi (Litchi chinensis, ), pineapple, etc "Akhtar et. al. (2010)" [20] and their juice, pulp or peel can be used for fortification to develop value added products. The mango pulp can be mashed, pasteurized, frozen and then dehydrated and directly incorporated into the product mix at the time of processing; this method of fortification is known to significantly increase the acidity of yoghurt when the procedure was carried out to develop value-enriched yoghurt "Jayalalitha et. al. (2015)" [21].

\subsection{Fortification of Vitamin D into food products}

Vitamin D or calciferol is yet another example of a micronutrient that has a significant role to play in boosting the immune system of our body. It is mainly produced in our skin on exposure to sunlight but can also be obtained through the food that we consume. Mainly two classes of vitamin D can be obtained through food and they are - vitamin $D_{2}$ (ergocalciferol) and vitamin $\mathrm{D}_{3}$ (cholecalciferol). Speaking of natural sources from which these classes of vitamin D can be obtained, vitamin $\mathrm{D}_{3}$ is abundant in animal sources and vitamin $D_{2}$ is found in plant based foods. Therefore, these natural sources can be utilized to obtain vitamin D from them and fortify them in regular staple food products or immunity building products. Experiments have been carried out on fortification of bread with vitamin D from time to time. In breads, pastries,etc, yeasts are added as a leavening agent at the time of preparation of the dough. A study shows that vitamin $\mathrm{D}_{2}$ is synthesized in Saccharomyces cerevisiae (baker's yeast) when treated with about $254 \mathrm{~nm}$ UV radiation and these yeasts can then be mixed with the other ingredients for bread processing and incubated "Bogale et. al. (2018)" [22]. The outcome will be a vitamin $\mathrm{D}_{2}$ fortified bread loaf. Vitamin $D_{3}$ can be taken from an artificial source like dry cholecalciferol powder and used as a fortificant. As vitamin D is fat soluble "Ravisankar et. al. (2015), Gomis et. al. (2000)" $[23,24]$, it generally requires a lipid-based food vehicle or a lipid carrier in food to be fortified uniformly "Yang et. al. (2013)" [25]. The cholecalciferol powder can therefore be added to the starch coated gelatin and sucrose matrix along with edible fats as carriers to obtain evenly fortified baked bread "Natri et. al. (2006)" [26].Apart from breads, lipid based foods like milk, milk products, oils, margarines, etc are mainly fortified with vitamin D "Gupta et. al. (2014)" [27]. A research work done on fortification of pasteurized, processed cheese with vitamin $D_{3}$ suggests that two types of dry cholecalciferol powder namely - water dispersible powder and 


\section{International Journal of Engineering Applied Sciences and Technology, 2020 \\ Vol. 5, Issue 6, ISSN No. 2455-2143, Pages 163-169 \\ Published Online October 2020 in IJEAST (http://www.ijeast.com)}

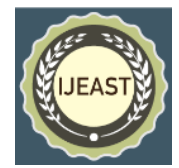

fat dispersible powder can be used for the process. In case of the water dispersible form, a particular amount of the powder was taken and was dissolved in the distilled water in a way that $1 \mathrm{ml}$ of the prepared solution corresponds to fortification level of vitamin $\mathrm{D}_{3}$ for $1 \mathrm{lb}$ of cheese, and for oil dispersible powder, another dilution was made with a known amount of powder in corn oil such that $1 \mathrm{ml}$ of that solution corresponds to the level of vitamin $\mathrm{D}_{3}$ fortification for about $1 \mathrm{lb}$ of cheese "Upreti et. al. (2002)" [28]. So these are some of the significant methods of fortification of the two forms of vitamin $\mathrm{D}$ that has been considered for this article.

\subsection{Fortification of Vitamin $E$ in different food items}

Vitamin $\mathrm{E}$ is the last immunity boosting vitamin whose fortification will be discussed in details. Since it is a fat soluble vitamin, fat-based food items are generally considered to be fortified with this vitamin as it will be easily dispersed uniformly in such a food item. Generally cooking oils are fortified with vitamin $\mathrm{E}$ where it plays the double role of acting as an immunity booster as well as a natural antioxidant thus helping in the preservation of the oil. However, in certain cases after the application of certain processes, vitamin $\mathrm{E}$ can be incorporated into water-based food products as well. It can even be fortified in fruits and fruits are known to have great moisture content. One such research points out to the development of Vitamin E fortified freshly cut apple fruit (Fuji) and the method that was applied to achieve the fortification is vacuum impregnation "Zhao et. al. (2005)" [29]. 20\% HFCS (High Fructose Corn Syrup), 1\% HPMC (hydroxypropyl methylcellulose), 1\% CC (calcium caseinate), $0.4 \% \alpha$-tocopherol acetate and certain other reagents were used to prepare the fortifying solution. This solution was then used to fortify the cut pieces of apples and vitamin E content was determined and found to be fairly high after the fortification. Vacuum impregnation (VI) is basically the process of partially removing the gas from within the pores of a food material and substituting it with a liquid of choice "Fito et. al. (2001)" [30]. Another category of products that is commonly fortified with vitamin $\mathrm{E}$ are the beverages. Vitamin $\mathrm{E}$ is very much heat sensitive, so in a particular research project that was concerned with the fortification of beverages, encapsulation of vitamin $\mathrm{E}$ was done to increase its heat stability. When encapsulated vitamin $\mathrm{E}$ was added to the orange emulsion beverage, greater retention of the vitamin was observed in the product after its heat treatment "Raikos et. al. (2017)" [31]. However, a large number of research works are not available on the fortification of random staple food items with vitamin $\mathrm{E}$ as vitamin $\mathrm{C}$ and vitamin $\mathrm{A}$ are the two vitamins which are mainly focused on when it comes to fortification of micronutrients. Vitamin E is mainly looked up for its antioxidant properties when it comes to fortification. A number of research works are coming up nowadays that would finally explore the immunity boosting property of this vitamin.

\section{FORTIFICATION TECHNIQUES USING ZINC AS THE FORTIFICANT}

Zinc is one of the most important materials for human body. It is needed for immune functions, DNA synthesis, it involves in growth and skin care. It also helps to minimize the risks of various age-related diseases. Daily requirement of zinc in human body: for woman $(12 \mathrm{mg} /$ day $)$ and for man (15mg/day). Zinc fortification is recommended as an appropriate strategy to enhance population zinc status but the guidelines are needed for appropriate types and good level of zinc fortification in food products "Rosado et. al. (2003)" [32]. A number of fortification works have been carried out on zinc. Many cereals have been fortified with zinc and zinc compounds from time to time to increase their nutrition density as staple food items consumed by people across the world.A research work was conducted on the fortification of whole rice grains using zincwhere parboiling of the paddy was chosen as the step where the grains were fortified "Prom-uthai et. al. (2010)" [33]. It was concluded from the research that parboiling is supposed to be an effective step in rice milling where the zinc can be incorporated into the grains. Another research by B. Tripathi and K. Patel suggests that Sorghum (Sorghum vulgare) and the cereal Pearl Millet (Pennisetumg laucum) can be processed into flour and that flour can be fortified using the compound of zinc stearate as the fortificant "Tripathi et. al. (2010)" [34]. Also, another paper from the same respective pair of researchers shows that the flour obtained from finger millets (Eleucinecoracana) can also be fortified with compounds like zinc oxide and zinc stearate "Tripathi et. al. (2010)" [35]. This process of fortifying the flours with zinc compounds is a cost effective process and was mainly carried out with the intention of serving the underprivileged section of our society. Apart from these, foods like porridge cereals and breakfast flour were also fortified with zinc over the past 20 years "Hess et. al. (2009), Brown et. al. (2010)"[36, 37].

\section{ANTIOXIDANT FORTIFICATIONS}

Antioxidants are any substance, when present at lower concentration than oxidizable substrates, significantly oppose or inhibit oxidation of those substrates "Durazzo et. al. (2019)"'[38]. In our body, antioxidants control the formation of free radicals. That is why antioxidants are considered as the essential part of optimal health. But the deficiency of antioxidants may result in wide range of human diseases "Shastri et. al. (2016)" [39]. Some studies have indicated that consumption of antioxidant-rich foods is beneficial to human health. Some of the natural antioxidants that stand out for their powerful activities in human body are epigallocatechin gallate, quercetin, curcumin, Resveratrol, hydroxytyrosol, astaxanthin, lycopene, dihydroquercetin and lignans "Nemzer et. al. (2019)" [40]. So fortification of foods with antioxidants is important. As customers demand more and more natural products so fortification of yogurts with natural antioxidant preservatives can be done. In case of fortification of yogurts with natural antioxidants, there are no significant changes in the yoghurt $\mathrm{pH}$ and nutritional value, in comparison with control samples (yogurt without any additive) "Caleja et. al. (2016)" [41]. Fortification of rice with antioxidants is also 


\section{International Journal of Engineering Applied Sciences and Technology, 2020 \\ Vol. 5, Issue 6, ISSN No. 2455-2143, Pages 163-169 \\ Published Online October 2020 in IJEAST (http://www.ijeast.com)}

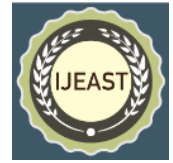

possible as white rice is a staple food, widely consumed worldwide. Using conventional cooking process white rice can be fortified with antioxidant compounds, extracted from leaves of the traditional herb spearmint "Igoumenidis et. al. (2016)" [42]. Berry juice fortification with antioxidants can also be done. The anthocyanins provide antioxidant activities in the black berry. But these anthocyanins degrade during the processing and storage of juice. So by maintaining high anthocyanin concentrations in berry juices may lead to greater antioxidant and health benefits for the consumer "Stebbins et. al. (2017)" [43]. As we know that consumption of alcohol has so many harmful effects on human body, so fortification of alcoholic beverages with the antioxidants present in the tea reduces the harmful effects. This fortification can decrease the liver ALP, replenish antioxidants and it can also improve the nutritional status of the body "Wachira et. al. (2016)" [44].

\section{VARIOUS DIFFICULTIES OF FORTIFICATION WITH THE MICRONUTRIENTS AND ANTIOXIDANTS}

There are a number of hardships that are faced while fortifying any food item with a certain micronutrient or a number of micronutrients. Any level of vitamins and minerals cannot be simply incorporated into the food item without the determination of their proper dosage. The recommended dietary allowance of the different vitamins and minerals must be taken care of, and accordingly, the dosage for the particular food shall be calculated. Excess amount of vitamin intake through fortified foods can lead to the risk of hypervitaminosis "Liberato et. al. (2006)" [45]. Also, the bioavailability of the different fortified micronutrients and antioxidants should be checked to ensure that the fortified food becomes a fully functional food. The bioavailability factor is some very important criteria for the development of any immunity boosting products. There are immunity boosting vitamins like vitamin $\mathrm{C}$ that are degraded due to heat processing. So these kinds of micronutrients require special fortification processes when they are to be fortified in foods that undergo heat treatment (an example can be the encapsulation of vitamin $\mathrm{C}$ when it is to be fortified in milk or milk based products). Furthermore, some of the vitamin are fat soluble and others are water soluble. Among the immunity boosting vitamins, vitamins $\mathrm{A}, \mathrm{D}$ and $\mathrm{E}$ are fat soluble only vitamin $\mathrm{C}$ is water soluble. So when choosing the food for fortification, fat based foods are easier to fortify and more efficient when fortified with fat soluble vitamins, and water based food items are easy carriers for water soluble vitamins. Given below is the table that summarizes the nutrients studied in this review work and the various associated features: -

Table-1: General summary

\begin{tabular}{|c|l|l|}
\hline $\begin{array}{l}\text { Immunity } \\
\text { Boosting } \\
\begin{array}{l}\text { Nutrients } \\
\text { studied }\end{array}\end{array}$ & $\begin{array}{l}\text { Fortification } \\
\text { vehicles } \\
\text { discussed }\end{array}$ & $\begin{array}{l}\text { Important } \\
\text { fortification } \\
\text { methods pointed } \\
\text { out }\end{array}$ \\
\hline Vitamin A & Vegetable oil, & Discontinuous \\
\hline
\end{tabular}

\begin{tabular}{|c|l|l|}
\hline & $\begin{array}{l}\text { Sugar, } \\
\text { Biofortified sweet } \\
\text { potato, Lassi, } \\
\text { Biscuits }\end{array}$ & $\begin{array}{l}\text { cooling } \\
\text { crystallization (for } \\
\text { sugar) }\end{array}$ \\
\hline Vitamin C & $\begin{array}{l}\text { Raw milk, } \\
\text { Cottage cheese, } \\
\text { Lemonades, } \\
\text { Yoghurt }\end{array}$ & $\begin{array}{l}\text { Liposomal } \\
\text { encapsulation (for } \\
\text { raw milk) }\end{array}$ \\
\hline Vitamin D & $\begin{array}{l}\text { Bread loaf, } \\
\text { Pasteurized } \\
\text { processed cheese, }\end{array}$ & $\begin{array}{l}\text { UV radiation } \\
\text { treatment of } \\
\text { Saccharomyces } \\
\text { cerevisiae(for bread } \\
\text { loaves) }\end{array}$ \\
\hline Vitamin E & $\begin{array}{l}\text { Apples, Orange } \\
\text { emulsion drink }\end{array}$ & $\begin{array}{l}\text { Vacuum } \\
\text { impregnation (for } \\
\text { apples) }\end{array}$ \\
\hline Zinc & $\begin{array}{l}\text { Whole rice grains, } \\
\text { Sorghum flour, } \\
\text { Pearl Millet flour, } \\
\text { Finger millet flour }\end{array}$ & $\begin{array}{l}\text { Fortification with } \\
\text { zinc compounds } \\
\text { for Sorghum, pearl } \\
\text { millet and finger } \\
\text { millet flour ) }\end{array}$ \\
\hline Antioxidants & $\begin{array}{l}\text { Yogurt, White } \\
\text { rice, Berry juice }\end{array}$ & $\begin{array}{l}\text { Incorporation of } \\
\text { natural ingredients } \\
\text { for rice ) }\end{array}$ \\
\hline
\end{tabular}

Table-2: Suitable choice of food vehicles for vitamin fortification:

\begin{tabular}{|c|c|c|}
\hline $\begin{array}{l}\text { Vitamins } \\
\text { to be fortified }\end{array}$ & \begin{tabular}{lr}
\multicolumn{1}{c}{ Nature } & $\begin{array}{r}\text { of } \\
\text { food } \\
\text { suitable } \\
\text { vehicle }\end{array}$
\end{tabular} & $\begin{array}{l}\text { Food vehicles } \\
\text { generally chosen }\end{array}$ \\
\hline Vitamin A & $\begin{array}{l}\text { Fat-based } \\
\text { food items }\end{array}$ & $\begin{array}{l}\text { Milk, margarine, } \\
\text { rice, oils, sugar, } \\
\text { cereals }\end{array}$ \\
\hline Vitamin C & $\begin{array}{l}\text { Water-based food } \\
\text { items }\end{array}$ & $\begin{array}{l}\text { Milk, fruit juices, } \\
\text { wheat flour, cheese }\end{array}$ \\
\hline Vitamin D & $\begin{array}{ll}\text { Fat-based food } \\
\text { items }\end{array}$ & $\begin{array}{lr}\text { Cereals, } & \text { bread, } \\
\text { butter } & \text { and } \\
\text { margarine } & \end{array}$ \\
\hline Vitamin E & $\begin{array}{l}\text { Fat-based } \\
\text { items }\end{array}$ & $\begin{array}{l}\text { Corn, any kind of } \\
\text { cooking oils }\end{array}$ \\
\hline
\end{tabular}

\section{DISCUSSION AND CONCLUSION}

In this particular review paper, we focused solely on the study of fortification of randomly selected staple food items with the five micronutrients and antioxidants rather than focusing on the development of hardcore immunity boosting products. This has been done with the intention to study and understand the pre-existing techniques used for food fortification and the types of nutrients and the foods that were chosen to be fortified with the concerned micronutrients. One of these techniques or a combination of several techniques can be considered by us for our upcoming works on the development of immunity boosting products. This review will also give us a better understanding on whether to use natural 


\section{International Journal of Engineering Applied Sciences and Technology, 2020 \\ Vol. 5, Issue 6, ISSN No. 2455-2143, Pages 163-169 \\ Published Online October 2020 in IJEAST (http://www.ijeast.com)}

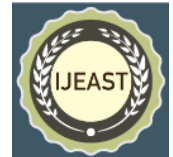

ingredients for fortification, or go for some artificial synthetic sources. From the study conducted, it became evident that out of all the micronutrients present, vitamins $\mathrm{A}, \mathrm{C}, \mathrm{D}$ and $\mathrm{E}$ and the mineral zinc are the ones that are responsible for boosting our immunity. It is also necessary to determine how the micronutrients shall be incorporated into the product so that the factors like stability of micronutrients, bioavailability, and recommended dosage can be properly maintained. Encapsulation of vitamins is one of the trending ways to increase the thermal stability of vitamins. Apart from the vitamins and minerals, antioxidants also play a key role in boosting our immune responses. Therefore, fortification of antioxidants into products has also been studied in details. There are various difficulties faced during fortification as well. One of these difficulties is concerned with the selection of the food for fortification. The food that is to be fortified should be a staple, commonly available one and should be selected as per the nature of the micronutrient. It has been observed from the research papers that in case of vitamin fortification, mostly artificial synthetic sources of vitamins like water soluble and fat soluble vitamin powders or compounds like retinyl palmitate (for vitamin A) are used for fortification purposes. For antioxidants, natural sources are mainly in demand. After the fortification is done, the last important factor is to check the shelf life of the final product and ensure its effectiveness for a long time. So, any one of the techniques mentioned in this paper might be utilized later on to develop a functional immunity boosting product.

\section{ACKNOWLEDGEMENT}

The authors of this review paper would like to express their gratitude to all the faculty members of the Department of Food Technology, Guru Nanak Institute of Technology for providing all the necessary guidance required for this article.

\section{REFERENCES}

[1]McCullough, F., Northrop-Clewes, C., Thurnham, D., 1999, "The effect of vitamin A on epithelial integrity", Proceedings of the Nutrition Society, Volume 58, Issue 2, ( pp. 289-293).

[2]Chen, Q., Jones, D., Stone, P., Ching, L., Chamley, L., 2009, "Vitamin C Enhances Phagocytosis of Necrotic Trophoblasts by Endothelial Cells and Protects the Phagocytosing Endothelial Cells from Activation", Placenta, Volume 30, Issue 2, (pp. 163-168).

[3]Aranow, C., 2011, "Vitamin D and the Immune System", Journal of investigative medicine, Volume 59, Issue 6, (pp. 881-886).

[4]Lee, G., Han, S., 2018, "The Role of Vitamin E in Immunity", Nutrients, Volume 10, Issue 11, (pp. 1614).

[5]Polcz, M., Barbul, A., 2019, "The Role of Vitamin A in Wound Healing", Nutrition in Clinical Practice, Volume 34, Issue 5, (pp. 695-700).

[6]Darlow, B., Graham, P., Rojas-Reyes, M.,2016, "Vitamin A supplementation to prevent mortality and short- and long- term morbidity in very low birth weight infants", Cochrane Database of Systematic Reviews.

[7]Gonçalves, A., Estevinho, B., Rocha, F.,2017, "Design and characterization of controlled-release vitamin A microparticles prepared by a spray-drying process", Powder Technology, Volume 305, (pp. 411-417).

[8]Wiseman, E., Dadon, S., Reifen, R., 2017, "The vicious cycle of vitamin A deficiency: A review", Critical reviews in food science and nutrition, Volume 57, Issue 17, (pp. 37033714).

[9]Laillou, A., Hafez, S., Mahmoud, A., Mansour, M., Rohner, F., Fortin, S., Berger, J., Ibrahim, N., MoenchPfanner, R., 2012, "Vegetable oil of poor quality is limiting the success of fortification with vitamin A in Egypt", Food and nutrition bulletin, Volume 33, Issue 3, ( pp.186-193).

[10]Walters, D., Ndau, E., Saleh, N., Mosha, T., Horton, S., 2019, "Cost-effectiveness of sunflower oil fortification with vitamin A in Tanzania by scale", Maternal \& child nutrition, Volume 15.

[11]Quintana-Hernandez, P., Maldonado-Caraza, D., Cornejo-Serrano, M., Villalobos-Oliver, E., 2020, "Development of a process for sugar fortification with vitamin-A”, Revista Mexicana de IngenieríaQuímica, Volume 19, Issue 3, (pp. 1163-1174)

[12]Low, J., Arimond, M., Osman, N., Cunguara, B., Zano, F., Tschirley, D., 2007, "A food-based approach introducing orange-fleshed sweet potatoes increased vitamin A intake and serum retinol concentrations in young children in rural Mozambique", The Journal of nutrition, Volume137, Issue 5, (pp. 1320-1327).

[13]Chawla, R., Sivakumar, S., Mishra, S., 2018, "Fortification of lassi with vitamin A using natural vegetable powders", International Journal of Chemical Studies, Volume 6, Issue 2, (pp. 2631-2635).

[14]Thomas, P., Abraham, L., Dharmapalan, B., 2018, "Physio-chemical and Sensory Properties of Biscuit Fortified with Carrot Powder", International Journal of Food and Fermentation Technology, Volume 8, Issue 2, (pp. 217-221).

[15]Carr, A., Maggini, S., 2017, "Vitamin C and immune function", Nutrients, Volume 9, Issue 11, (pp. 1211).

[16]Sharma, R., Lal, D., 2005, "Fortification of milk with microencapsulated vitamin C and its thermal stability", Journal of Food Science and Technology -Mysore, Volume 42, Issue 2, (pp. 191).

[17]Kirby, C., Whittle, C., Rigby, N., Coxon, D., Law, B., 1991, "Stabilization of ascorbic acid by microencapsulation in liposomes", International Journal of Food Science \& Technology, Volume 26, Issue 5, (pp. 437-449).

[18]Sweeney, M., Ashoor, S., 1989, "Fortification of cottage cheese with vitamins A and C", Journal of dairy science, Volume 72, Issue 3, (pp. 587-590).

[19]Tamer, C., Yekeler, F., Çopur, Ö., Incedayi, B., Suna, S., 2017, "A study of fortification of lemonade with herbal extracts", Food Science and Technology, Volume 37, Issue 1, (pp. 45-51).

[20]Akhtar, N., Rahman, M., Muslim, T., 2010, "Comparative Study of the Content of Vitamin C in Fresh Fruits and Different Types of Food Prepared from them", Dhaka 


\section{International Journal of Engineering Applied Sciences and Technology, 2020 \\ Vol. 5, Issue 6, ISSN No. 2455-2143, Pages 163-169 \\ Published Online October 2020 in IJEAST (http://www.ijeast.com)}

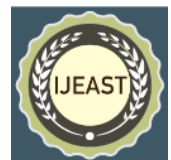

University Journal of Science, Volume 58, Issue 1, (pp. 5557).

[21]Jayalalitha, V., Manoharan, A., Balasundaram, B., Elango, A., 2015, "Formulation of Value Enriched Yoghurt with Soy Milk and Mango Pulp", Journal of Nutrition \& Food Sciences, Volume 5, Issue 6, (pp. 1).

[22]Bogale, T., 2018, "Use of bio-enriched yeast and stability of its vitamin $\mathrm{D}_{2}$ in wheat dough baking", MedCrave Group LLC.

[23]Ravisankar, P., Reddy, A., Nagalakshmi, B., Sai, O., Kumar, B., Anvith, P., 2015, "The comprehensive review on fat soluble vitamins", IOSR Journal of Pharmacy, Volume 5, Issue 11, (pp. 12-28).

[24]Gomis, D., Fernández, M., Alvarez, M., 2000, "Simultaneous determination of fat-soluble vitamins and provitamins in milk by microcolumn liquid chromatography", Journal of Chromatography, Volume 891, Issue 1, (pp. 109114).

[25]Yang, Z., Laillou, A., Smith, G., Schofield, D., MoenchPfanner, R., 2013, "A review of vitamin D fortification: implications for nutrition programming in Southeast Asia", Food and nutrition bulletin, Volume 34, Issue 2_suppl1, (pp. S81-S89).

[26]Natri, A., Salo, P., Vikstedt, T., Palssa, A., Huttunen, M., Kärkkäinen, M., Salovaara, H., Piironen, V., Jakobsen, J., Lamberg-Allardt, C., 2006, "Bread fortified with cholecalciferol increases the serum 25-hydroxyvitamin D concentration in women as effectively as a cholecalciferol supplement", The Journal of nutrition, Volume 136, Issue 1, (pp. 123-127).

[27] Ritu, G., Gupta, A., 2014, "Fortification of foods with vitamin D in India", Nutrients, Volume 6, Issue 9, (pp. 36013623).

[28]Upreti, P., Mistry, V., Warthesen, J., 2002, "Estimation and Fortification of Vitamin $\mathrm{D}_{3}$ in Pasteurized Process Cheese", Journal of dairy science, Volume 85, Issue 12, (pp. 3173-3181).

[29]Zhao, Y., Park, S., Leonard, S., Traber, M., 2005, "Vitamin E and mineral fortification in fresh-cut apples (Fuji) using vacuum impregnation", Nutrition \& Food Science, Volume 35, Issue 6.

[30]Fito, P., Chiralt, A., Barat, J., Andrés, A., MartínezMonzó, J., Martínez-Navarrete, N., 2001, "Vacuum impregnation for development of new dehydrated products", Journal of Food Engineering, Volume 49, Issue 4, (pp. 297$302)$.

[31]Raikos, V., 2017, "Encapsulation of vitamin E in edible orange oil-in-water emulsion beverages: Influence of heating temperature on physicochemical stability during chilled storage", Food Hydrocolloids, Volume 72, (pp. 155-162).

[32]Rosado, J., 2003, "Zinc and Copper: Proposed Fortification Levels and Recommended Zinc Compounds", The Journal of Nutrition, Volume 133, Issue 9, (pp. 2985S2989S).

[33]Prom-u-thai, C., Rerkasem, B., Cakmak, I., Huang, L., 2010, "Zinc fortification of whole rice grain through parboiling process", Food Chemistry, Volume 120, Issue 3, (pp. 858-863).
[34]Tripathi, B., Chetana, Platel, K., 2010, "Fortification of sorghum (Sorghum vulgare) and pearl millet (Pennisetumglaucum) flour with zinc", Journal of Trace Elements in Medicine and Biology, Volume 24, Issue 4, (pp. 257-262).

[35]Tripathi, B., Platel, K., 2010, "Finger millet (Eleucinecoracana) flour as a vehicle for fortification with zinc", Journal of Trace Elements in Medicine and Biology, Volume 24, Issue 1, (pp. 46-51).

[36]Hess, H., Brown, K., 2009, "Impact of zinc fortification on zinc nutrition", Food and Nutrition Bulletin, Volume 30, Issue 1_suppl1, (pp. S79-S107).

[37]Brown, K., Hambidge, K., Ranum, P., 2010, "Zinc fortification of cereal flours: Current recommendations and research needs", Food and Nutrition Bulletin, Volume 31, Issue 1_suppl1, (pp. S62-S74).

[38]Durazzo, A., Lucarini, M., Souto, E., Cicala, C., Caiazzo, E., Izzo, A., Novellino, E., Santini, A., 2019, "Polyphenols: A concise overview on the chemistry, occurrence, and human health", Phytotherapy Research, Volume 33, Issue 9, (pp. 2221-2243).

[39]Shastri, A., Srivastava, R., Jyoti, B., Gupta, M., 2016, "The antioxidants-scavengers of free radicals for immunity boosting and human health/overall well being", Journal of Contemporary Medical Research, Volume 3, Issue 10, (pp. 2918-2923).

[40]Nemzer, B., Yashin, A., Vedenin, A., Yashin, Y., Yashunsky, D., Nifantiev, N., Kalita, D., 2019, "Selected Powerful Natural Antioxidants: Structure, Food Sources, Antioxidant Activities, and Important Health Benefits", Journal of Food Research, Volume 8, Issue 1, (pp. 60-79).

[41Caleja, C., Barros, L., Antonio, A., Carocho, M., Oliveira, M., Ferreira, I., 2016, "Fortification of yogurts with different antioxidant preservatives: A comparative study between natural and synthetic additives", Food chemistry, Volume 210, (pp. 262-268).

[42]Igoumenidis, P., Lekka, E., Karathanos, V., 2016, "Fortification of white milled rice with phytochemicals during cooking in aqueous extract of Mentha spicata leaves. An adsorption study", LWT - Food Science and Technology, Volume65, (pp. 589-596).

[43]Stebbins, N., Howard, L., Prior, R., Brownmiller, C., Mauromoustakos, A., 2017, "Stabilization of anthocyanins in blackberry juice by glutathione fortification", Food \& function, Volume 8, Issue 10, (pp. 3459-3468).

[44]Wachira, F., Kimutai, S., Wanyoko, J., Kinyanjui, T., Karori, S., Muthiani, A., 2016, "Determination of Residual Catechins, Polyphenolic Contents and Antioxidant Activities of Developed Theaflavin-3,3'- Digallate Rich Black Teas", Food and Nutrition Sciences, Volume 7, (pp. 180-191).

[45]Liberato, S., Pinheiro-Sant'Ana, H., 2006, "Fortification of industrialized foods with vitamins", Revista de Nutrição, Volume 19, Issue 2, (pp. 215-231). 